\title{
PENGARUH PERTUMBUHAN KREDIT TERHADAP DINAMIKA INDUSTRI DENGAN METODE MARKOV SWITCHING MODEL
}

\section{THE EFFECT OF CREDIT GROWTH ON DYNAMICS INDUSTRY WITH THE METHOD OF MARKOV SWITCHING MODEL}

\author{
Aulia Keiko Hubbansyah ${ }^{1}$, Eva Rabita ${ }^{2}$ \\ ${ }^{1}$ Progam Management Studies Faculty of Economics, University of Djuanda Bogor \\ ${ }^{2}$ Program Library Science Studies Faculty of Culture, University of North Sumatera \\ Email :_keikohubbansyah91@gmail.com
}

\begin{abstract}
This research objective is to analyze the effect of credit growth on the industrial growth in Indonesia. In analyzing the effect, this research classifies the industrial growth into two states or regimes. So that, it is possible to identify the effect of credit growth in each regime. By applying Markov Switching Model, the result shows that the effect of credit growth on the industrial growth is greater in the low growth regime compare to the high growth regime. It indicates that the credit growth could play an important role in countercyling the time being trends. In regard to the transitional probabilities, this research also find that the transition of the state from low to high growth regime or vice versa tends to be persistent.
\end{abstract}

Keywords: Credit Growth, Industrial Growth, Markov Switching Model

\begin{abstract}
ABSTRAK
Penelitian ini bertujuan untuk menganalisis dampak pertumbuhan kredit terhadap pertumbuhan industri. Dalam menganalisis dampaknya, penelitian ini mengklasifikasi pertumbuhan industri ke dalam dua state atau regime. Sehingga, dapat diidentifikasi dampak pertumbuhan kredit pada masing-masing regime. Dengan menggunakan Markov Switching Model, hasilnya didapati bahwa pengaruh pertumbuhan kredit terhadap pertumbuhan industri lebih besar pada regime pertumbuhan rendah dibandingkan regime pertumbuhan tinggi. Hal ini mengindikasikan bahwa pertumbuhan kredit dapat memainkan peran dalam menstabilisasi tren pertumbuhan yang sedang berlangsung. Sementara itu, terkait dengan probabilitas transisional, studi ini juga mendapati bahwa transisi dari regime pertumbuhan rendah ke pertumbuhan tinggi dan sebaliknya cenderung bersifat persisten.
\end{abstract}

Kata Kunci: Pertumbuhan Kredit, Pertumbuhan Industri, Model Markov Switching 


\section{PENDAHULUAN}

Hubungan antara pertumbuhan kredit dan aktivitas industri menjadi salah satu isu utama yang dibahas di dalam studi ekonomi. Levine, et.al, (1998) dan Korkmaz (2015), menemukan adanya pengaruh positif pertumbuhan kredit terhadap pertumbuhan ekonomi. Pentingnya peran kredit dalam menggerakkan sektor riil ekonomi juga ditemui Schularick, et.al, (2012) yang menyimpulkan bahwa credit growth menjadi prediktor finansial krisis yang paling penting.

Strategisnya peran sektor finansial bagi perkembangan sektor ekonomi riil tercermin dari tidak adanya satu pun sektor dalam perekonomian yang sepenuhnya dapat terhindar dari dinamika yang terjadi di sektor finansial (Baur, 2012; Aizenman, et al, 2013). Bahkan resesi ekonomi yang dipicu oleh krisis finansial (keuangan) memiliki dampak negatif yang lebih dalam dan persisten (Claessens, et.al, 2011; Antonakakis, et.al, 2015).

Secara keseluruhan, temuan-temuan studi yang membahas mekanisme melalui mana kredit mempengaruhi sektor riil mendapati bahwa negara yang memiliki sektor perbankan yang bekerja lebih baik akan mampu bertumbuh dengan lebih cepat. Sejalan dengan itu, diketahui juga kinerja sistem finansial yang baik akan mengatasi kendala pembiayaan eksternal yang dihadapi perusahaan yang membuat industri menjadi lebih mudah untuk berkembang (Bongini, et.al, 2017; Levine, et.al, 2004).

Meski telah cukup mampu menjelaskan pola hubungan antara pertumbuhan kredit dan aktivitas riil ekonomi, pada studi-studi sebelumnya masih didapati adanya kekurangan. Dimana sebagian besar dari studi-studi di atas hanya berupaya menganalisis pengaruh pertumbuhan kredit terhadap aktivitas sektor riil ekonomi secara monolitis.

Berkaitan dengan hal di atas, penelitian ini bermaksud mengembangkan studi-studi sebelumnya dengan berusaha mengidentifikasi perubahan pola pengaruh pertumbuhan kredit terhadap aktivitas industri, baik ketika pertumbuhan industri dalam kondisi rendah maupun tinggi. Karena itu, harus diidentifikasi dulu kondisi (state) pertumbuhan industri yang rendah dan tinggi berdasarkan data yang dimiliki. Untuk kemudian bisa dilihat bagaimana perubahan pola (besaran) pengaruh pertumbuhan kredit terhadap aktivitas industri pada masing-masing kondisi (tinggi/rendah) tersebut.

Agar bisa mencapai tujuan tersebut, studi ini menggunakan Markov Switching Model (MSModel) sebagai metode analisis. Dengan MSModel dapat diidentifikasi regime pertumbuhan industri (yang diklasifikasikan ke dalam pertumbuhan tinggi dan rendah). Kelebihan lain dari MSModel adalah dapat diketahui nanti berapa besar kemungkinan (probability) suatu kondisi berpindah dari keadaan pertumbuhan industri rendah ke keadaan pertumbuhan industri tinggi, dan sebaliknya. Dengan demikian, dapat diketahui nantinya apakah kondisi suatu keadaan (tinggi/rendah) cenderung persisten atau tidak.

Adapun yang menjadi obyek kajian dari studi ini adalah aktivitas kredit dan industri di Indonesia. Ini karena di Indonesia, perkembangan industri mengalami stagnasi. Bahkan, dalam beberapa tahun terakhir, trennya malah menunjukkan gejala deindustrialisasi. Ini menjadi persoalan karena tren deindustrialisasi di Indonesia diikuti dengan pertumbuhan sektor jasa informal. Oleh karena itu, penting untuk diketahui bagaimana peran pertumbuhan kredit dalam mempengaruhi perkembangan industri di Indonesia.

Dalam operasionalnya, frekuensi pengamatan menggunakan data kuartalan dengan panjang periode selama 31 tahun (1985q1-2015q4). Panjangnya periode pengamatan diperlukan agar keterkaitan antara pertumbuhan kredit dan industri dapat dijejaki dengan lebih optimal. 


\section{MATERI DAN METODE}

\section{Penelitian Sebelumnya}

Terdapat beberapa studi sebelumnya yang membahas persoalan yang dikaji dalam studi ini. Levine, et.al, (1998) dengan menggunakan pendekatan cross-country, mendapati adanya hubungan positif dan signifikan antara level perkembangan perbankan dengan pertumbuhan ekonomi suatu negara. Dengan menekankan fokus yang sama, studi lanjutan Levine, et.al, (2000) menekankan adanya keterkaitan yang erat antara perkembangan financial intermediary dengan pertumbuhan ekonomi jangka panjang. Schularick, et.al, (2012), setelah mempelajari perekonomian 14 negara maju selama periode 1870-2008, menemukan bahwa faktor-faktor finansial memainkan peran penting sebagai determinan siklus pada sektor riil. Hal yang sama juga didapati oleh Braun, et.al, (2005), dimana setelah melakukan analisis terhadap 100 negara dengan rentang periode pengamatan selama 40 tahun, ia menemukan bahwa kredit memiliki pengaruh yang signifikan terhadap kinerja industri. Lebih lanjut, Braun, et.aIndonesia (2005) juga mendapati kalau industri yang bergantung pada pembiayaan eksternal akan menerima dampak negatif yang lebih parah ketika ekonomi mengalami resesi.

Studi yang dilakukan Korkmaz (2015) dengan menggunakan 10 negara Eropa sebagai sampelnya mendapati bahwa domestic credit di kesepuluh negara yang menjadi sampelnya terbukti tidak berpengaruh terhadap inflasi, akan tetapi memiliki pengaruh yang signifikan terhadap sektor riil ekonomi yang diproxykan dengan pertumbuhan ekonomi. Sementara itu, studi Oni, et.al, (2014), menekankan fokus berbeda. Dimana di dalam analisisnya dampak pertumbuhan kredit terhadap sektor rii dipisah berdasarkan klasifikasi sektor, yakni industri dan pertanian (agrikultur). Hasilnya, dengan menjadikan Nigeria sebagai sampel, Oni, et.al,
(2014) menemukan bahwa kredit perbankan memiliki pengaruh yang signifikan terhadap pertumbuhan output pada sektor manufaktur, baik untuk jangka pendek maupun panjang. Sementara itu, untuk sektor pertanian, tidak terdapat pengaruh yang signifikan. Oleh karena itu, menurut Oni, et.al, (2014) untuk mempercepat pertumbuhan output pada sektor riil, alokasi kredit perbankan, khususnya untuk sektor manufaktur diperbesar.

\section{Metode}

Data yang akan digunakan dalam studi ini meliputi credit growth dan index of industrial production growth. Seluruh data yang digunakan berfrekuensi kuarteran. Frekuensi ini dipilih karena frekuensi kuarteran relatif mampu mengidentifikasi dan mendokumentasi fitur siklus finansial dan bisnis dengan baik (Claessens, et al, 2011).

Tabel 1. Data dan Sumber Data

\begin{tabular}{lcccc} 
Negara & Variabel & $\begin{array}{c}\text { Nama } \\
\text { Variabel }\end{array}$ & Tahun & Sumber \\
& Industrial & IIP & & \\
\hline Indonesia & $\begin{array}{c}\text { Production } \\
\text { Bank }\end{array}$ & & 1984- & Datastream \\
& Credit & BC & & \\
\hline
\end{tabular}

Secara operasional bank credit growth akan digunakan sebagai proxy pertumbuhan kredit (Claessen, et al, 2011; Borio, et al, 2012). Dipilihnya bank credit growth sebagai proksi pertumbuhan kredit karena di Indonesia peran perbankan (secara relatif) sangat dominan sebagai sumber utama pembiayaan eksternal bagi sektor industri. Hal ini yang membuat karakteristik sektor finansial Indonesia bersifat bank-based (Nasution, 2004). Sedangkan, index of industrial production growth digunakan sebagai proxy pertumbuhan industri, sekaligus menggambarkan kondisi siklus bisnis yang berlangsung di sektor riil perekonomian. 
Estimasi model dalam penelitian ini menggunakan Markov Switching Model (MS Model) yang dikembangkan oleh Hamilton (1989). MSModel, yang dikenal juga dengan regime switching model merupakan salah satu model time series non linier yang populer (Utari, et.al, 2012). Melalui MSModel dapat diidentifikasi sejumlah regime atau state dari variabel terikat berdasarkan kondisi data yang dimiliki. Dalam prakteknya, MSModel terbukti efektif diterapkan pada nonlinier dynamic yang biasanya ditemui pada data time series ekonomi finansial.

$$
y_{t}=u_{s_{\mathrm{t}}}+\sigma_{S_{\mathrm{t}}} \varepsilon_{t}
$$

Persamaan (1) merupakan bentuk dasar dari MSModel dimana $\varepsilon_{\mathrm{t}} \sim N\left(0, \sigma_{s t}{ }^{2}\right)$ dan $S_{t}=1$, $2, . ., k$ menunjukkan indikator state yang tidak teramati, dimana $k$-state mengikuti proses Markov ergodik yang mengikuti persamaan di bawah ini:

$$
\begin{array}{r}
\operatorname{Prob}\left(S_{t+j}=j \mid S_{t}=i_{s} S_{t-1}=k_{s \ldots s}\right) \\
\quad=\operatorname{Prob}\left(S_{t+1}=j \mid S_{t}=i\right)=P_{i j j_{s}}
\end{array}
$$

Dimana $i, j=1,2, \ldots, k$ yang memperlihatkan terdapat $k$ kemungkinan state yang berbeda. Adapun matriks transisinya adalah sebagai berikut:

$$
P=\left[\begin{array}{cccc}
P_{11} & P_{21} & \cdots & P_{\mathrm{a}} \\
P_{12} & P_{22} & \cdots & P_{\mathrm{an}} \\
\vdots & \vdots & \ddots & \vdots \\
P_{1 k} & P_{2 k} & \cdots & P_{a k}
\end{array}\right]
$$

Kemungkinan perubahan dari satu state ke state yang lain, yang disebut dengan kemungkinan transisi, ditampilkan dengan matriks di atas. Oleh karena $P_{i j}$ melambangkan peluang, maka semuanya merupakan bilangan nonnegatif dan tidak lebih dari satu. Secara matematis, kondisi ini dapat ditulis menjadi:

$$
0 \leq P_{i j} \leq 1, i=1,2, \ldots, k
$$

$$
\sum_{j=1}^{k} P_{i j}=1, i=1,2, \ldots, k
$$

Estimasi MSModel dalam penelitian ini menggunakan MSModel dynamic regression, dengan menambahkan satu variabel eksogen yang dependen terhadap kondisi state dalam hal ini pertumbuhan kredit. Sehingga, bentuk dasar dari MSModel dapat ditulis menjadi:

$$
y_{t}=u_{g}+Z_{t} \beta_{g}+\varepsilon_{s, t}
$$

Di mana $Z_{t} \beta_{s}$ merupakan merupakan eksogen yang dependen terhadap kondisi state.

\section{ANALISIS DAN PEMBAHASAN}

Sebelum masuk pada pembahasan utama penelitian, di bagian awal akan diuraikan lebih dahulu statistik deskriptif dari variabel yang dianalisis. Adapun informasinya dapat dilihat pada tabel di bawah ini:

Tabel 1. Statistik Deskriptif

\begin{tabular}{cc}
\hline \multicolumn{2}{c}{ Periode 1985q1 - 1993q4 } \\
\hline BC (Bank Credit) & IIP \\
0.151 & $0.103^{* *}$ \\
$(0.03)$ & $(0.01)$ \\
\hline \multicolumn{2}{c}{ Periode 2003q1 - 2015q4 } \\
\hline BC (Bank Credit) & IIP \\
0.159 & $0.03^{* *}$ \\
$(0.01)$ & $(0.001)$ \\
\hline
\end{tabular}

Nilai mean variabel. Nilai yang ada di dalam kurung adalah nilai standar error.

** signifikan pada taraf 1 persen.

Tabel 1 di atas menunjukkan nilai ratarata pertumbuhan kredit dan industri di Indonesia. Agar dapat dilihat pola perubahannya, nilai rata-rata variabel diperoleh dengan membagi periode analisis ke dalam dua bagian, yakni periode sampai dengan 5 tahun sebelum krisis finansial Asia 1998 (periode 1985q1-1993q4) dan 5 tahun 
setelah krisis sampai dengan akhir periode penelitian (2003q1-2015q4).

Jika diamati, kedua variabel menunjukkan tren pergerakan nilai rata-rata yang berbeda. Rata-rata Pertumbuhan kredit di Indonesia pasca krisis (15.9 persen) didapati sedikit lebih tinggi dibandingkan periode pra krisis Asia (15.1 persen). Ini artinya, secara deskriptif, kondisi pembiayaan kredit perbankan di Indonesia relatif sudah mengalami pemulihan setelah terkena krisis yang parah pada 1998. Walaupun demikian, secara statistik (uji t), tidak terdapat bukti yang menunjukkan adanya perbedaan nilai rata-rata pertumbuhan kredit pada periode pra dan pasca krisis Asia. Ini artinya, nilai rata-rata pertumbuhan kredit pada periode pra dan pasca krisis cenderung sama.

Sementara itu, untuk variabel IIP yang merupakan proxy pertumbuhan industri, diketahui mengalami penurunan, dari yang sebelumnya sebesar 10.3 persen pada periode sebelum krisis menjadi hanya 3 persen pasca krisis. Ini berarti bahwa pasca krisis, sektor industri Indonesia belum mampu bertumbuh dan melampui kinerja pertumbuhan Industri seperti ketika sebelum krisis terjadi. Dugaan ini diperkuat, dimana secara statistik dapat dibuktikan adanya perbedaan yang signifikan antara nilai rata-rata pertumbuhan industri pada periode pra dan pasca krisis.

Secara faktual, pesatnya pertumbuhan industri yang terjadi di Indonesia pada periode sebelum krisis Asia mengakibatkan terjadinya transformasi ekonomi dengan cukup masif. Ada perubahan struktur dalam perekonomian, dari yang semula berbasis pertanian menjadi lebih terdiversifikasi karena menguatnya peran sektor manufaktur. Dengan pesatnya kenaikan sumbangan sektor industri terhadap perekonomian lebih dari 20 persen terhadap PDB pada akhir 1990, maka menurut standar UNIDO (Organisasi Pembangunan Industri PBB), ketika itu Indonesia dikelompokkan sebagai ekonomi semi-industri (Wie, 2006).
Krisis finansial yang melanda ASEAN pada periode 1997/1998 memberi implikasi buruk terhadap perkembangan sektor industri. Meski seluruh negara ASEAN terimbas krisis, yang paling parah terkena imbas negatifnya adalah Indonesia. Dari studi komparatif yang dilakukan oleh Bank Dunia mengenai dampak krisis terhadap sektor industri diketahui bahwa 76.3 persen perusahaan Indonesia mengalami penurunan produksi sejak krisis pecah pada Juli 1997. Sementara itu, untuk Malaysia dan Thailand, terjadi penurunan produksi industri masing-masingnya adalah 69.6 persen dan 73.1 persen.

Sektor industri Indonesia juga mengalami penurunan terbesar dalam pemanfaatan kapasitas, yakni dari 74.5 persen pada paruh pertama 1997 menjadi 59.2 persen pada paruh pertama tahun 1998. Untuk sektor industri di Malaysia dan Thailand, masing-masing angkanya adalah 78.5 persen menjadi 66.3 persen, dan 71.4 persen menjadi 61.8 persen. Penurunan kinerja sektor industri di Indonesia mengakibatkan perekonomian mengalami kontraksi hingga -14.8 persen pada tahun 1998. Sektor industri Indonesia sendiri mengalami kontraksi sebesar -12.9 persen. Setidaknya diidentifikasi ada dua hal pokok yang menyebabkan turunnya tingkat produksi industri. Pertama, merosotnya permintaan domestik dan dampak negatif depresiasi Rupiah terhadap biaya input impor. Kedua, tingginya biaya modal akibat kenaikan suku bunga yang tajam.

Setelah membahas statistik deskriptif variabel penelitian, selanjutnya masuk pada pembahasan utama penelitian.

Setelah mengalami kontraksi pertumbuhan yang sangat tajam pada saat krisis, sektor industri Indonesia secara perlahan mulai pulih, dan bertumbuh kembali. Setidaknya, sektor ini tercatat masih mampu bertumbuh positif yakni sebesar 3 persen. Hanya memang, tingkat pertumbuhan yang dicapai masih jauh lebih kecil dibandingkan pada periode pra krisis. 
Tabel 2. Hasil Estimasi Markov Switching Model

\begin{tabular}{rlrrrr}
\hline & IIP & Koefesien & Std. Error & $\mathrm{z}$ & $\mathrm{P}>|\mathrm{z}|$ \\
\hline State 1 & BC & 0.323 & 0.032 & 10.03 & 0.000 \\
& Constanta & -0.048 & 0.014 & -4.68 & 0.000 \\
State 2 & & & & & \\
& BC & 0.074 & 0.037 & 1.99 & 0.047 \\
& Constanta & 0.097 & 0.008 & 11.71 & 0.000 \\
& Sigma & & & & \\
& P11 & 0.064 & 0.004 & & \\
& P21 & 0.928 & 0.037 & & \\
\end{tabular}

Tabel 2 menunjukkan hasil estimasi $M S$ Model untuk menguji secara empirik pengaruh pertumbuhan kredit terhadap aktivitas industri, yang diproxykan lewat pertumbuhan industri. Melalui metode MSModel diidentifikasi dua kondisi (state) pada pertumbuhan industri, yakni state 1 dan state 2. Dari nilai yang diestimasi, diketahui bahwa state 1 merujuk pada regime pertumbuhan industri rendah di mana rata-rata pertumbuhan pada kondisi ini sebesar -4.8 persen. Dengan kata lain, kondisi pertumbuhan negatif pada state 1 menggambarkan kondisi perlambatan (kontraksi).

Di sisi lain, state 2 merujuk pada regime pertumbuhan industri tinggi, dimana diketahui nilai rata-rata pertumbuhan industri mencapai 9.7 persen. Dengan dapat diidentifikasinya regime pertumbuhan industri, baik itu regime pertumbuhan rendah maupun tinggi, maka dapat diketahui pola pengaruh pertumbuhan kredit terhadap pertumbuhan industri untuk kedua state yang ada yakni, state 1 dan state 2.

Secara keseluruhan, terlepas dari apapun kondisinya - apakah state 1 atau state 2- studi ini mendapati adanya pengaruh yang positif dan signifikan antara pertumbuhan kredit terhadap pertumbuhan industri. Dengan demikian temuan pada studi ini selaras dan mendukung temuan pada sejumlah penelitian sebelumnya. Sekaligus juga mengafirmasi adanya peran penting dari sektor pembiayaan eksternal dalam hal ini kredit terhadap pertumbuhan industri (Levine, et.al, 1998; Levine, et.al, 2000; Braun, et.al, 2005; Oni, et.al, 2014; Korkmaz, 2015).
Selain mendapati fakta di atas, studi ini juga menemukan adanya perbedaan besaran pengaruh dari pertumbuhan kredit terhadap pertumbuhan industri pada masing-masing regime. Dimana pada regime atau state 1 , yang menggambarkan kondisi kontraksi pertumbuh-an, pengaruh pertumbuhan kredit terhadap pertumbuhan industri diketahui lebih besar dibandingkan pada saat state 2. Ini mengindi-kasikan bahwa, secara relatif, peran kredit jauh lebih krusial di dalam menggerakkan dan menumbuhkan kegiatan industri ketika kondisi sektor industri tengah mengalami periode per-tumbuhan negatif (kontraksi). Sebaliknya, ketika kondisi pertumbuhan industri berada dalam state 2 regime pertumbuhan industri tinggi dampak pertumbuhan kredit, sekali-pun didapati masih positif, besarannya relatif lebih kecil.

Temuan di atas mengindikasikan peran countercyclical yang dapat dimainkan oleh kredit dalam kaitannya dengan pertumbuhan industri. Dimana dalam situasi industri yang resesif, akses pembiayaan eksternal dalam bentuk kredit perbankan, dapat membantu industri keluar dari situasi sulit (Brei, et.al, 2015). Sebaliknya, dalam situasi industri yang bertumbuh akseleratif, pemberian kredit dapat digunakan sebagai instrumen untuk menahan munculnya perilaku spekulatif dari para pelaku industri yang bisa berujung pada krisis. Oleh karena itu, dengan kemampuan countercycli-cal yang dimilikinya, kredit dapat berperan sebagai stabiliser dalam perekonomian (Brei, et.al, 2015). 
Berkaitan dengan kemampuan countercyclical dari kredit, Brei, et.al, (2015), yang menganalisis 764 bank yang tersebar di 50 negara, mendapati bahwa bank yang dimiliki oleh pemerintah lebih cenderung melakukan ekspansi kredit sekalipun situasi siklus bisnis (sektor riil) tengah mengalami krisis dibanding bank milik privat (swasta). Berbeda dengan Brei, et.al, (2015), studi yang dilakukan oleh Ibrahim (2016) menunjukkan bahwa perilaku pemberian kredit yang dilakukan bank, secara agregat, bersifat prosiklikal. Akan tetapi, pada waktu dilakukan segregasi sampel ke dalam kategori bank konvensional dan bank syariah, Ibrahim (2016) menemukan kalau perilaku prosiklikal hanya dijumpai pada bank konvensional. Adapun bank syariah didapati lebih tidak sensitif terhadap siklus bisnis, yang berarti lebih bersifat countercyclical.

Dengan demikian, temuan studi ini yang mendapati adanya potensi countercyclical yang dapat dimainkan kredit dalam situasi kontraksi (state 1) dan ekspansif (state 2) pada sektor riil yang diproxykan oleh pertumbuhan industri selaras dengan hasil studi Brei, et.al, (2013) dan Ibrahim (2016).

Tabel 3. Probabilitas Transisi

\begin{tabular}{ccc}
\hline $\begin{array}{c}\text { Dari/Ke } \\
\text { Kondisi }\end{array}$ & 1 & 2 \\
\hline 1 & 0.928 & 0.072 \\
2 & 0.045 & 0.955 \\
\hline
\end{tabular}

Tabel di atas menginfomasikan besaran probabilitas transisi dari satu ke kondisi (state 1) ke kondisi yang lain (state 2). Dalam hal ini, probabilitas transisi dari state 1 ke state 1 adalah 0.928. Dengan kata lain, sekali kondisinya berada pada state 1 , maka kecenderungannya adalah pertumbuhan industri akan tetap ada di dalam state ini (regime pertumbuhan rendah). Sekalipun demikian, ada probabilita sebesar 0.072, kondisi pertumbuhan industri berubah ke state 2. Demikian juga halnya untuk kasus state 2, dimana besaran probabilitas transisi dari state 2 ke state 2 adalah 0.955 , dengan probabilitas sebesar 0.045 untuk berubah menjadi state 1. Konstelasi nilai probabilita yang ada menunjukkan bahwa kedua kondisi, baik state 1 maupun state 2 mengindikasikan tendensi yang persisten.

Tabel 4. Ekspetasi Durasi

\begin{tabular}{cc}
\hline Ekspetasi Durasi & Estimasi \\
\hline State 1 & 13.94 \\
State 2 & 22.14 \\
\hline
\end{tabular}

Kondisi yang persisten dari tiap-tiap state diindikasikan selain dari nilai probabilitasnya, juga dari proyeksi ekspetasi durasi pada tiaptiap state. State 1 memiliki ekspetasi durasi selama 13.94 kuarter. Artinya, pertumbuhan industri yang negatif situasi kontraksi pada kegiatan industri diekspetasi akan berlangsung selama 13.94 kuarter, atau sekitar 3.5 tahun. Di sisi lain, state 2 memiliki ekspetasi durasi selama 22.14 kuarter. Dengan kata lain, era pertumbuhan industri yang positif yakni, situasi pertumbuhan ekspansif diekspetasi akan berlangsung selama 22.14 kuarter, atau sekitar 5.5 tahun. Dengan demikian, studi ini mendapati bahwa ekspetasi durasi pada fase/regime ekspansif lebih lama dibandingkan fase/regime fase pertumbuhan industri yang kontraktif.

\section{SIMPULAN DAN IMPLIKASI}

Studi ini bertujuan menganalisis dampak pertumbuhan kredit terhadap pertumbuhan industri di Indonesia yang diklasifikasikan ke dalam state atau regime pertumbuhan rendah dan tinggi. Dengan menggunakan Markov Switching Model (MSModel) diketahui adanya perbedaan dampak pertumbuhan kredit pada regime pertumbuhan rendah dan pertumbuhan tinggi pada industri. Di mana pada state atau regime pertumbuhan industri rendah, pengaruh pertumbuhan kredit didapati lebih besar diban- 
dingkan ketika state atau regime pertumbuhan industri tinggi. Ini mengindikasikan bahwa, secara relatif, peran pertumbuhan kredit lebih strategis dalam menggerakkan sektor industri ketika sedang berada dalam fase kontraktif. Dengan demikian, studi ini menekankan aspek countercyclical dari kredit dalam menstabilisasi kerja sektor industri yang diproxykan dari tingkat pertumbuhannya. Selain itu, terkait dengan probabilitas transisi dari state 1 (pertumbuhan rendah) ke state 2 (pertumbuhan tinggi) dan sebaliknya, studi ini mendapati kecenderungan yang persisten. Dalam arti, butuh waktu yang relatif lama bagi sektor industri untuk bertransisi dari regime pertumbuhan rendah ke regime pertumbuhan tinggi, dan juga sebaliknya.

\section{UCAPAN TERIMA KASIH}

Ucapan terima kasih kepada Universitas Sumatera Utara dan Universitas Djuanda Bogor serta semua pihak yang terkait dalam penelitian ini.

\section{DAFTAR PUSTAKA}

Aizenmann, J., Pinto, B., Sushko, V. (2013). Financial Sector Ups and Downs and the Real Sector in the Open Economy: Up by the Stairs, Down by the Parachute. Emerging Market Review, 16. Page $1-30$.

Antonalakis, N., Breiteniechner, M., Johann, S. (2015). Business Cycle and Financial Cycle Spillover in the G7 Countries. The Quarterly Review of Economics and Finance, 58. Page $154-162$.

Baur, D. G. (2012). Financial Contagion and the Real Economy. Journal of Banking and Finance, 36. Page 2680 - 2692.

Bongini, P., Malgorzata, I., Pawel, S., Bartosz, W. (2017). Financial Development and Economic Growth: The Role of ForeignOwned Banks in CESEE Countries. Sustainability, 9.
Borio, C. (2012). The Financial Cycles and Macroeconomics: What Have We Learnt? BIS Working Paper 395.

Braun, M., Larrain, B. (2005). Finance and the Business Cycle : International, InterIndustry Evidence. The Journal of Finance, 9.

Brei, M., Schclarek, A. (2015). A Theoretical Model of Bank Lending: Does Ownership Matter in Times of Crisis?. Journal of Banking and Finance, 50. Page 298 - 307.

Claessens, S., Kose, M. A., Marco, E. T. (2011). Financial Cycles: What? How? When?. IMF Working Paper /11/76.

Ibrahim, M. (2016). Business Cycle and Bank Lending Procyclicality in a Dual Banking System. Economic Modelling, 55. Page $127-134$.

Jorda, O., Schularick, M., Taylor, A. (2013). When Credit Bites Back. Journal of Money, Credit and Banking, 45. Page 328.

Korkmaz, S.(2015). Impact of Bank Credit on Economic Growth and Inflation. Journal of Applied Finance and Banking, 5. Page $57-69$.

Levine, R. (2004). Finance and Growth: Theory and Evidence. NBER Working Paper No. 10766

Levine, R., Loayza, N., Beck, T. (2000). Financial Intermediation and Growth: Causality and Causes. Journal of Monetary Economics, 46. Page $31-77$.

Levine, R., Zervos, S. (1998). Stock Markets, Banks, and Economic Growth. The American Economic Review, 88. Page $537-558$.

Oni, O., Akinlo, E., Oladepo, E. (2014). Impact of Bank Credit on the Real Sector: Evidence from Nigeria. Globall Journal of Business Research, 8. Page 39 -47 . 